\title{
Hydraulic resistances of suspended flows in bedrooms with a moving bottom
}

\author{
Kenesbay Baimanov", Gulmurat Shaniyazov, Torebek Uzakov, Ruslan Baimanov \\ Karakalpak State University, Nukus, Uzbekistan
}

\begin{abstract}
The results of some existing theoretical and experimental studies of hydraulic resistances of open flows in moving channels are considered. Possible reasons for the inconsistency of the results of various studies of hydraulic resistance in open channels with increased roughness are indicated. The analysis of mass field data on the Darcy (Shezi) coefficient of canals in alluvial soils and a sandy mobile bed is carried out. It was confirmed that the channels of these categories are characterized by a mixed zone of hydraulic resistance, and regularities were revealed that take into account the features of the real resistance zone of earthen channels. Based on the analysis of the smoothly varying flow of open flows and the corresponding theory of the boundary layer and the law of the logarithmic distribution of velocities, the calculated dependencies are obtained, making it possible to determine the resistance of open flows concerning natural conditions.
\end{abstract}

\section{Introduction}

Calculation of the hydraulic resistance of pressure head and open streams moving in rigid and moving channels is sometimes necessary when solving various technical problems. In most of these problems, one has to deal with the turbulent motion of fluids, for which there is no closed system of equations. The urgency of the problem of resistance of channels and the absence of strict solutions have more than two centuries of history. Back in 1935, prof. PF Gorbachev [1] published more than 130 formulas for calculating the Shezy coefficient, proposed by that time. In the future, the number of formulas of hydraulic resistance continued to grow, mainly related to open earthen channels.

A large number of works both in the CIS and abroad have been devoted to the study of hydraulic resistance in open canals and rivers with increased channel roughness. However, the inconsistency of the results does not allow us to establish the quantitative patterns of changes in the coefficient of hydraulic resistance from the main parameters and the qualitative relationships. The inconsistency of the conclusions made by various experimenters can also be explained by the difference in the ranges of variation of hydraulic parameters in experiments (A.P. Zegzhda, S.Kh. Abalyants, A.V. Karaushev, F.M. Exner, D. Kennedy, V.S. Knorozam, etc.).

\footnotetext{
*Corresponding author: ruslan_kenesbaevich@list.ru
} 
Many researchers (M.A. Mostkov, M.F. Sribny, A.D. Altshul, and others) have established the dependence of the Shezy coefficient on the hydraulic slope. The last of these formulas was proposed by OM Aivazyan [2].

Modern dependencies for the Shezi $\mathrm{C}$ coefficient are applied quite reliably at $\mathrm{R} \leq$ (3-5) $\mathrm{m}$, that is, in the range of the N.N. Pavlovsky's formula. It is known that N.N. Pavlovsky established the ambiguity of the relationship between the Shezy coefficient and the hydraulic radius $\mathrm{R}$. Later $\mathrm{G}$. Marchi recorded a relative decrease in resistance in large channels and an obvious dependence of their throughput on the shape of the channel. S.Kh. Abalyants [3] established that in several cases, the channels operate in the smooth channel mode, but nevertheless did not find it possible to introduce the Reynolds number Re into the formulas for $\mathrm{C}$ in explicit form and modified the functions $\mathrm{C}(\mathrm{R})$ taking into account that, that in channels with a small range of changes in flow rates and water viscosity, $\mathrm{Re}$ mainly depends on the hydraulic radius $\mathrm{R}$.

According to the results of special experiments, K. Shikh and N. Grigg [4] showed that with the same hydraulic radii and physical roughness of the tray surface, the average flow rates in it differed by more than 2 times. The same experiments revealed the influence of the relative channel width $\beta=B / h$ on the Manning roughness coefficient. The dependence $n$ $=\mathrm{f}(\mathrm{B} / \mathrm{h})$ has long been known, but its quantitative estimates are very contradictory.

The results of studies evaluating modern formulas for calculating the Shezy coefficient, carried out using a large number (more than 480 measurements) of field research data in a wide range of parameters of earthen canals [2], suggest that being practically uniform, these formulas do not reflect the true nature of hydraulic resistance of earthen channels, since the movement in them belongs to the mixed zone of resistance $[3,5]$.

The problem of resistance of open earthen channels is in a special situation. River beds and canals are deformable. For streams, the channels of which are composed of finegrained alluvium, this circumstance is of decisive importance. Energy losses in plain rivers with clarified water, due to the resistance of only sandy ridges, account for up to $90 \%$ of the total losses along the length [6,7]. Therefore, in the formulas (A.N. Lyapin, V.S. Knoroz, F.Engulenda, B.F. For the values $\lambda \_\Delta$ and $J_{-} \Delta$, they give theoretical dependences, where the hydraulic resistance of the channel flow with a ridge bottom is almost unambiguously related to the slope of the ridge $\Delta M$ and the ratio $\Delta H$. In the article [6], for the height $\Delta^{-}$and the steepness of the ridges $\Delta$ of the clarified flows, the dependences are derived together with the equation of BF Snischenko [7].

In the transition to identifying similar dependencies for the hydraulic resistance in a turbid flow, one has to turn to the analysis of the classical equations of the averaged motion of the dispersoid and the energy balance of the suspended flow. However, being derived only for the conditions of smoothly varying currents, these equations turn out to be of little use in identifying the interaction between suspended and bottom sediments that occurs under conditions close to the non-smooth variability of bottom currents. Based on the experimental research of N.A. Mikhailova [3], it can be noted that the disturbed transit flow over the basement of the ridge is a kind of wave motion with the subordination of the gradients of hydromechanical pressure $(1 / \rho)(\partial \rho / \partial x)$. As equations of non-smoothly changing motion in the article $[9,20]$, dependencies and methods are used inherently in the description of wave processes; that is, wave equations are used. Thus, in recent years, general results have been outlined regarding resistance with non-smoothly varying movement in open channels.

Theoretical and experimental studies carried out to date do not give an unambiguous answer to the question of the effect of turbid flow on hydraulic resistance. The nature of suspension on friction at the wall is such that suspension particles, lingering or moving slowly near the wall and changing its actual roughness, affect the hydraulic resistance. In this case, both an increase and a decrease in the hydraulic resistance can occur, depending 
on whether the wall roughness increases or decreases. In addition, numerous data indicate that the hydraulic resistance of the flow carrying the suspension increases due to the inhibition of its heavy suspension [3]. For a quantitative account of resistances, special experiments are required.

In our studies, we proceeded from the fact that the key issues of hydraulic resistance are: the ratio of roughness, kinematic characteristics, and the relationship of hydraulic resistance with the turbidity of the flow.

\section{Methods}

The main results of the work were obtained by the method of full-scale hydraulic research [10]. On several earthen canals in the Amu Darya river basin, studies of the kinematic structure of the flow and the effect of the amount of suspended matter in the flow on hydraulic resistance were carried out $[11,12]$. Analytical and generally accepted research methods were used.

The study of the distribution of the averaged velocities along the flow depth was carried out on the selected rectilinear sections of the channels. Basically, the measurements of the velocity distribution were carried out with a small-sized propeller of the GR-55 and GR-99 types on three verticals: the flow axis $0.5 \mathrm{~V}, 0.25 \mathrm{~V}$ to the right, and $0.25 \mathrm{~V}$ to the left of the axis along with the 5-6 point method on each vertical (surface, $0,2 \mathrm{~h}, 0.6 \mathrm{~h}, 0.8 \mathrm{~h}, 0.9 \mathrm{~h}$, and bottom). The data on the verticals in the middle part of the stream are averaged: depth as an arithmetic mean and velocities weighted averaged over relative depth. In total, more than 60 series of measurements were made in various channels with a flow rate of $60-375 \mathrm{~m} 3$ / $\mathrm{s}$ at flow rates $\vartheta=0.4-1.3 \mathrm{~m} / \mathrm{s}$.

Water samples to determine the vertical turbidity, where the flow rate was measured, were taken with a bottle of long-term filling, and the bottom turbidity was taken with an instantaneous bottle. The values of turbidity and fractional composition of sediments were determined in the SANIIRI laboratory. The water surface slope was determined using a slope rail installed at the beginning and at the end of the investigated section of the channels.

According to research data, the stable state of the canal section, when there is no siltation and erosion of the channel, we established from the conditions of equality of the average turbidity and size in the initial and final sections of the channel section. Despite the equality of the average turbidity and size in the sections, an increase in the bottom turbidity is sometimes observed by erosion, which changes the bottom topography and deposition on the upper layers of the stream. In the first case, the roughness coefficient $n$ increases, and in the second, it decreases.

\section{Results and Discussion}

Field studies of the mode of operation of earthen canals show that in some cases, "hydraulically smooth" and in others "hydraulically rough" modes of channel resistance are observed [5, 13, 14].

In the flow, under the influence of large-scale turbulent vortex formations, sediments are continuously weighed from the bottom and deposited on the bottom, and as a result of the exchange of sediments between the flow with the bottom, a bottom topography of a complex configuration is formed, which changes over time. In channels with a bottom made of sand, the main energy losses along the channel length are due to the resistance of the moving relief (ridge). 
In a turbulent flow, large-scale turbulent formations have a decelerating effect on the main flow movement and increase the hydraulic resistance of the channel when flowing around them. In addition, the change in channel resistance is influenced by the presence of suspended and bottom sediments in the flow [12].

Thus, the resistance of the channel and the granular roughness of the channel surface and channel forms (ridges and riffles) are determined by the intensity of the flow turbulence and the consumption of the part of the turbulent energy for weighing and transporting sediments. In channels with an alluvial channel covered with sandy sediments, at flow rates exceeding the limit for indestructibility or close to them, a ridge form of bottom sediments is observed, and at higher flow rates, bottom ridges, increasing in size, create increased resistance to flow movement up to a certain limit (possibly before the ridges are washed away). An increase in the flow velocities exceeding the limiting speed for erosion by more than two times leads to the washout of ridges, and a transition from ridge motion to a continuous attraction of bottom sediments occurs, which cause smoothing of all irregularities and the cessation of erosion, the process of flow movement passes into the second smooth stage, reducing resistance channel [14].

When more sediment enters the channel than it can transport, excess turbidity is deposited, and all irregularities in the channel roughness are leveled by sediment sedimentation. As a result of intensive sedimentation of sediments on the surface of the sediment, a layer highly saturated with sediments is formed, which has the properties of fluidity with increased viscosity [11]. In this case, the movement of two "different" fluids in terms of density is obtained, and the flow is stratified (stratification). Apparently, a layer of anomalous fluid of the Shvedov - Bingham type is formed in the bottom zone. This layer leads to a weakening of the decelerating effect of the channel on the movement of the flow. Thus, in the process of siltation and during the transition from the ridge movement to the continuous entrainment of bottom sediments, the flow creates a hydraulically smooth mode of channel resistance.

To analyze the regularity of changes in hydraulic resistances, we examined the data of more than 1570 observations [3], [14-19], conducted on 150 sections of earthen canals in some systems in Central Asia. Most of the observations refer to channels located in loamy, sandy loam, and fine sandy soils. These data were used to calculate the coefficients of resistance $\lambda$ and roughness $n$.

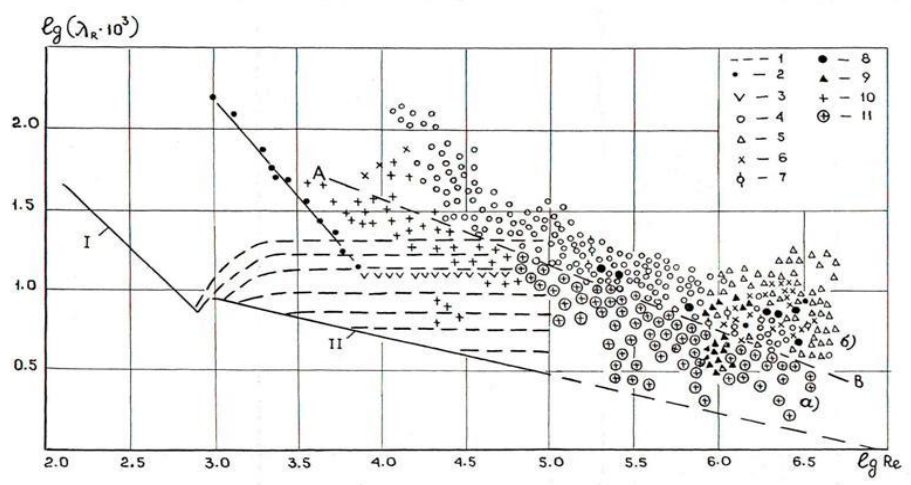

Fig. 1. Dependence of the hydraulic resistance coefficient on the number Reynolds (Nomogram K.I.Baimanov): 1 is graph of A.P. Zegzhda [15]; I is Poiseuille line; II is Bloisis line. 2 is laboratory data (stock mode) [2]; 3 is laboratory data (flow regime) [3]; 4 is channel of the Kyzketken irrigation system (1952-1953) (J> 0.00007); 5,6,7,8 are respectively, the Kyzketken, Suenli, Kegeyli, Kuvanyshjarma canals $(1976-78,1981-83,1985-90)(\mathrm{J}>0.00007) ; 9$ is channel feeding Kyzketken $(1981-86)(\mathrm{J}<0.00005)$; $10-11$ are canals with very small slopes $(\mathrm{J}<0.00005)$; 10 are inter-farm 
canals of rice systems (1987-91); 11 are on-farm canals of rice systems (1987-1991). Line AB is the border of the area of smooth (a) and rough (b) channels of earthen canals.

The drag coefficient values plotted on the graph of A.P. Zegzhd for open channels are shown in Fig. 1. This graph allows drawing the following conclusions:

1. The field of location of field points is outside the zone of the graph of dependence $\lambda=\lambda$ (Re, $\Delta(\mathrm{R}))$ A.P. Zegzhda, recommended for open streams.

2. There is a general tendency for the drag coefficient to decrease with an increase in the Reynolds number, where the smallest value of the drag coefficient is close to hydraulic smooth channels and the largest to hydraulic rough channels.

3. Judging by the nature of the location of full-scale points, based on the general relationship $\lambda=\lambda(\mathrm{Re}, \mathrm{J}, \mathrm{R})$ recommended in [2], it can be assumed that a mixed zone of resistance characterizes currents in earth channels. This zone, in the first approximation, can be divided into two areas: a) the area of the location of the points of the channels with very small slopes $(\mathrm{J}<0.00005)$ (to the left of the AB line) is the area for smooth channels of the channels; $b$ ) the area of the location of the canal points in the mode of ordinary watercourses $(\mathrm{J}>0.00007)$ (to the right of the AB line) is the area for rough channel channels. AB lines are drawn at the boundaries between these areas.

Considering that with a change in the flow velocity field, the channel roughness changes, that is, the size and shape of the ridges or the moving bottom topography, therefore, we will use the parameters of the kinematic structure of the flow, measured by us in the large channels of the lower reaches of the Amu Darya [14].

A simple and theoretically substantiated way to obtain a drag formula for hydraulically rough channels consists in the combined use of the velocity distribution formula and the average velocity deficit formula, in the form [16]:

$$
\frac{1}{\sqrt{\lambda}}=\frac{C}{\sqrt{2 g}}=\frac{1}{k} \ln \frac{h}{\Delta}+C_{3}
$$

$$
\text { where } \quad \mathrm{C}_{3}=\frac{u_{\Delta}}{u_{*}}-\frac{1}{k} \quad \text { is the constant of integration; } \quad \kappa=\frac{u_{*}}{u_{M}-u_{v}}
$$

Parman parameter, characterizing the intensity of vortex separation; $u \_m$ is maximum surface speed on the vertical; $u_{-}$v is average vertical speed; $\vartheta$ is average flow rate.

In formula (1), the height of the roughness protrusions $\Delta$ can be replaced by any value proportional to $\Delta$. In this case, it is only necessary to adjust the constants $\mathrm{C} \_3$ accordingly.

In experiments with water flow in open trays with fixed sandy roughness, Zegzhda found that $\mathrm{K}=0.4, \mathrm{C}_{-} 3=4.25$, and then the resistance formula obtained the form

$$
\frac{1}{\sqrt{\lambda_{R}}}=\frac{C}{\sqrt{2 g}}=4 \lg \frac{R}{\Delta}+4.25
$$

When applying resistance formulas containing the height of the roughness protrusions $\Delta$, the most difficult question is to determine the calculated (effective) value of $\Delta$. Based on his experiments, Zegzhda plotted a relationship curve between the height of the protrusions and the average particle diameter. From this curve, it can be seen that in the region d_av 1.5 $\mathrm{mm}$, the approximate ratio $\Delta \approx 1.6 \mathrm{~d} \_$av is satisfied. 


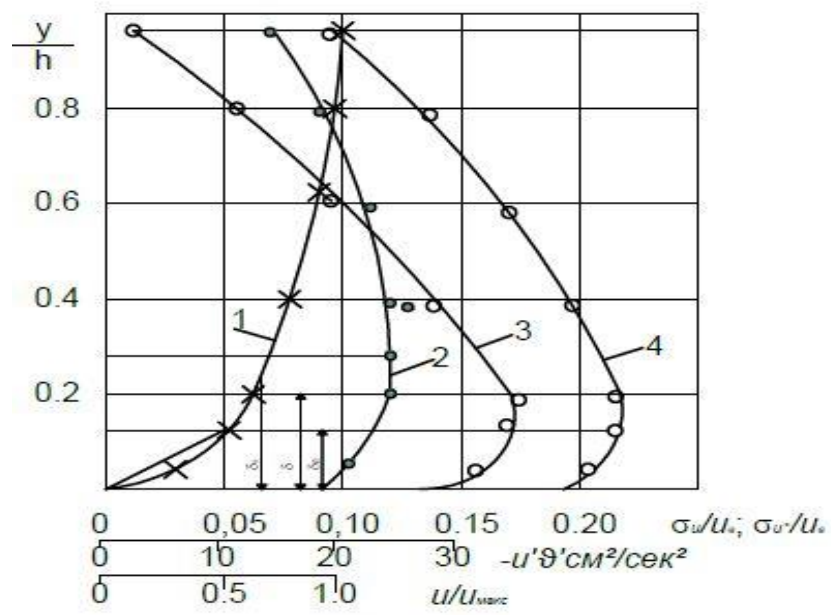

Fig. 2. Model of the structural mechanism of open flow turbulence: 1 is diagram of the distribution of longitudinal velocities along the vertical; 2,3 , and 4 are, respectively, $\frac{\sigma_{\vartheta}}{u_{\mathrm{B}}} \overline{u^{\prime}} \overline{\overline{\vartheta^{\prime}}}$ and $\frac{\sigma_{u}}{u_{B}}$ change along the flow depth $h$.

Determination of the effective height of roughness ridges in natural channels and channels is fraught with difficulties since the Shezy coefficient $\mathrm{C}$ in practical calculations is usually calculated not by dependences of the form (1), but by empirical formulas containing special "roughness coefficients" in place of $\Delta R$. Designers use the formulas of N.N. Pavlovsky and R. Manning more often than others. The simpler of the two is Manning's formula

$$
\mathrm{C}=\frac{1}{n} R^{1 / 6}
$$

where $\mathrm{n}$ is the roughness coefficient; $\mathrm{R}$ is the hydraulic radius.

As shown by the analysis carried out in [20], for an accelerated flow, the change in the local coefficient of hydraulic resistance $\lambda \_m$ in the sections of flow stabilization does not qualitatively correspond to Manning's formula, and its value may differ by a factor of 1.5 2.0 from the value according to Manning. These inaccuracies should be asked about the development of methods for calculating uneven motion. These methods can be based on the theory of the boundary layer, in which the drag coefficient is associated not with the depth of the flow but only with the thickness of the boundary layer $\delta$, which can be significantly less than $\mathrm{h}$ (Fig. 2).

The roughness of the watercourse bottom plays a decisive role in forming the profiles of turbulence characteristics. The position of the bottom layer is clearly formed by the inflection points on the horizontal pulsation velocity profile. The layer thickness $\delta$ is always greater than the roughness ridges.

Based on Newton's law of friction [21] for the boundary layer, we have:

$$
\tau_{\mathrm{o}}=\rho \vartheta_{*}^{2}=\mu \frac{u_{\delta}}{\delta}
$$

whence

$$
\delta=\frac{\mu}{\rho} \cdot \frac{1}{\vartheta_{*}} \cdot \frac{u_{\delta}}{\vartheta_{*}}=v \frac{1}{\vartheta_{*}} \cdot \frac{u_{\delta}}{\vartheta_{*}}
$$




$$
\delta=\frac{v \cdot \Delta}{\vartheta_{*}}
$$

where $\delta$ is the thickness of the boundary layer; $v=\mu / \rho$ is kinematic viscosity of the liquid; $\vartheta_{*}=\sqrt{g h J}$ is dynamic speed; $N=u_{\delta} / \vartheta_{*}$ is the stability parameter of the bottom layer; $u_{\delta}$ is the velocity at the boundary of the bottom layer with thickness $\delta$.

Considering the above factors and solving together with the drag formulas and Manning's formulas using the parameters of the distribution of velocities $\mathrm{K}$ and $\mathrm{N}$ according to the research data, we obtain a relationship between the roughness coefficient $\mathrm{n}$ and the thickness of the boundary layer $\delta$.

$$
n=\frac{B}{\sqrt{g} \sqrt{N}} \cdot \delta^{1 / 6}
$$

Substituting the resulting expression $\mathrm{n}$ in the Manning formula, we will have:

$$
\frac{\mathrm{C}}{\sqrt{g}}=\sqrt{\frac{2}{\lambda}}=\frac{0.95 \sqrt{N}}{B} \cdot\left(\frac{R}{\delta}\right)^{1 / 6}
$$

where $B$ is the experimental variable coefficient, determined by the graph $\mathrm{B}=\mathrm{f}(\mathrm{K})$ (Fig. 3).

Dependence (7) differs from the Manning - Strickler formula with a variable coefficient " $\delta$ " in place of "d." The coefficient $\left(\frac{0.95 \sqrt{N}}{B}\right)$ ranges from 5.5 to 8.5 , while for Strickler it is 6.67 , which is close to the average value of the variable coefficient.

The formula for determining the Shezy coefficient (7) is in good agreement with the data of field studies; its deviation from those calculated from the measurement data is +4.2 and $-4.8 \%$ and can be recommended for calculating the hydraulic resistance of easily deformed channels (Table 1).

If the distribution of velocities over the free cross-section is known, then using the drag formula (1), it is possible to determine the heights of the roughness protrusions $\Delta_{\ni}$ and the roughness coefficient $\mathrm{n}$, which are related to the Shezy coefficient $\mathrm{C}$ and the parameter K. According to the resistance formula of the logarithmic type, where the ratio of the bottom velocity at the height of the roughness protrusions $u_{\Delta}$ is applied to the dynamic speed $\vartheta_{*}$

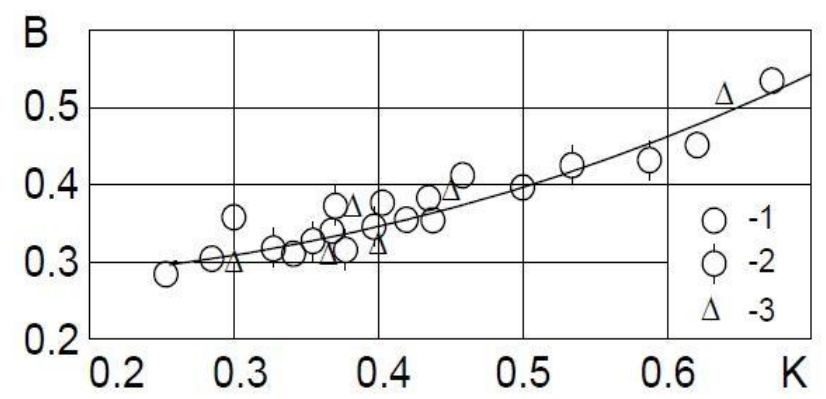

Fig. 3. Dependence of the experimental coefficient B on the parameter $K: 1$ is Kyzketken channel; 2 is Suenli channel; 3 is Kuvanyshjarma channel. 
Constant $\left(N=u_{\Delta} / \vartheta_{*} \approx\right.$ const $)$. Measurements of the distribution of averaged velocities by some researchers $[14,17]$ in earth canals show that the parameter $N$ is not a constant value but changes depending on the values of " $\mathrm{n}$ " and " $K$ "

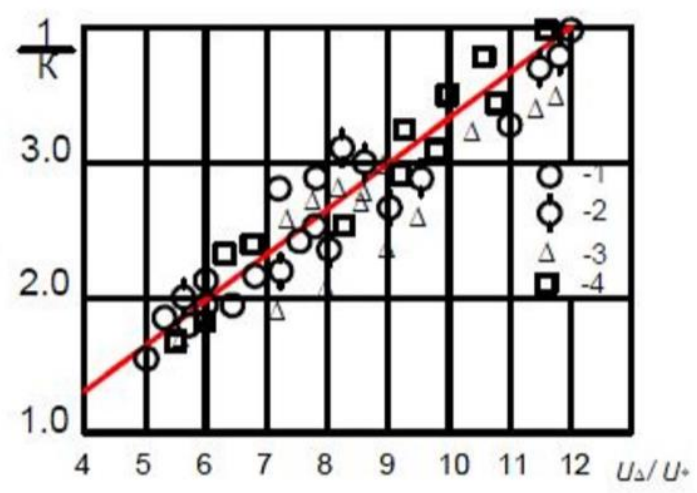

Fig. 4. Dependence of the velocity deficit $\left(\frac{1}{k}\right)$ on the parameter of the bottom area $N=\frac{u_{\Delta}}{u_{*}} \quad 1,2,3$ are the same as in Figure 3; 4 is Parallel channel Suenli.

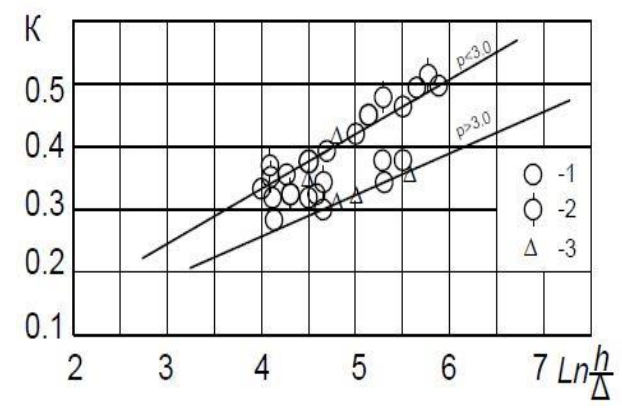

Fig. 5. Dependence of the parameter $\mathrm{K}$ on the relative roughness $(\mathrm{h} / \Delta)$ of the turbid flow (designation is the same as in Figure 3).

For a rough indelible channel, according to the measurements of I, Nikuradze, the ratio $u_{\Delta} / \vartheta_{*}$ at $\Delta=\mathrm{d}$ turned out to be equal to 8.5, V. I. Efremov - 7.4, V. I. Goncharov - 7.1. According to IK Nikitin, the velocity at the upper boundary of the boundary layer is $u_{\delta}=5,6 \vartheta_{*}$. From Vanoni's experiments, the value $u_{\Delta} \vartheta_{*}$ was obtained equal to 6.6 , and according to Coles' data for a smooth channel $u_{\Delta}=5,1 \vartheta_{*}$. The data of various authors $[3,8$, $9,17,21]$ show that the bottom velocity $u_{\Delta}$ is approximately equal to the velocity $u \delta$ at the upper boundary of the layer $\delta\left(u_{\Delta} \approx u_{\delta}\right)$ and the ratio $N=u_{\delta} / \vartheta_{*}$ can be considered a parameter of stability of the boundary layer. Based on the data of measurements of the distribution of averaged velocities, we constructed a graph of the dependence $\mathrm{N}=\mathrm{f}(\mathrm{K})$ (Fig. 4), according to which the dependence

$$
u_{\Delta}=u_{\delta}=\frac{1}{K} 3 \vartheta_{*}
$$

Here, at $\mathrm{K}=0.4$, we get $\mathrm{N}=7.6$, which is consistent with the data of Nikuradze and Efremov. 
Table 1. The measured parameters of the distribution of averaged velocities along the depth of the flow in the channels of the Amu Darya delta systems [14].

\begin{tabular}{|c|c|c|c|c|c|c|c|c|c|c|c|c|c|c|}
\hline №, & $\begin{array}{c}\overline{\bar{u}_{\mathrm{B}}}, \\
\mathrm{m} / \\
\mathrm{s}\end{array}$ & $\begin{array}{c}\bar{u}_{\Delta}, \\
\mathrm{m} / \\
\mathrm{s}\end{array}$ & $\begin{array}{c}\vartheta_{*} \\
\mathrm{~cm} / \\
\mathrm{s}\end{array}$ & $\frac{u_{\Delta}}{\vartheta_{*}}$ & $\begin{array}{c}\rho_{\mathrm{cp}}, \\
\mathrm{kg} / \mathrm{m}^{3}\end{array}$ & $\begin{array}{c}h_{M}, \\
\mathrm{~m}\end{array}$ & $i \cdot 10$ & $\begin{array}{c}\vartheta, \\
\mathrm{m} / \mathrm{s}\end{array}$ & $\begin{array}{l}R, \\
\mathrm{~m}\end{array}$ & $\begin{array}{c}K= \\
\frac{u_{*}}{u_{\mathrm{M}}-u_{\mathrm{B}}}\end{array}$ & $\begin{array}{l}\mathrm{u}_{\mathrm{n}}, \\
\mathrm{m} / \mathrm{s}\end{array}$ & $\frac{\mathrm{C}}{\sqrt{g}}$ & $\begin{array}{l}\frac{\mathrm{C}}{\sqrt{g}} \\
\text { ПО } \\
\text { (7) }\end{array}$ & $\begin{array}{l}\text { Di } \\
\text { v- } \\
\text { er- } \\
\text { ge } \\
\text { n- } \\
\text { ce }\end{array}$ \\
\hline \multicolumn{15}{|c|}{ channel Kizketken $\left(\mathrm{Q}=122 \ldots 345 \mathrm{~m}^{3} / \mathrm{c}\right)$} \\
\hline 1 & $\begin{array}{c}0.9 \\
7\end{array}$ & $\begin{array}{c}0.4 \\
6\end{array}$ & $\begin{array}{c}6.4 \\
8 \\
\end{array}$ & $\begin{array}{c}6.7 \\
0\end{array}$ & 0.58 & $\begin{array}{c}4.5 \\
0\end{array}$ & 105 & $\begin{array}{c}0.8 \\
8 \\
\end{array}$ & $\begin{array}{c}3.1 \\
3\end{array}$ & 0.43 & $\begin{array}{c}1.1 \\
4\end{array}$ & $\begin{array}{c}15 . \\
5\end{array}$ & $\begin{array}{c}16 . \\
4\end{array}$ & $-\overline{-}$ \\
\hline 2 & $\begin{array}{c}0.9 \\
9 \\
\end{array}$ & $\begin{array}{c}0.4 \\
8 \\
\end{array}$ & $\begin{array}{c}6.9 \\
5 \\
\end{array}$ & $\begin{array}{c}6.9 \\
0 \\
\end{array}$ & 1.72 & $\begin{array}{c}5.0 \\
3 \\
\end{array}$ & 98 & $\begin{array}{c}0.9 \\
6 \\
\end{array}$ & $\begin{array}{c}3.6 \\
6 \\
\end{array}$ & 0.44 & $\begin{array}{c}1.1 \\
5 \\
\end{array}$ & $\begin{array}{c}16 . \\
2 \\
\end{array}$ & $\begin{array}{c}16 . \\
0\end{array}$ & $\begin{array}{c}+1 . \\
2\end{array}$ \\
\hline 3 & $\begin{array}{c}0.9 \\
4 \\
\end{array}$ & $\begin{array}{c}0.4 \\
6 \\
\end{array}$ & $\begin{array}{c}6.9 \\
8 \\
\end{array}$ & $\begin{array}{c}6.6 \\
0 \\
\end{array}$ & 2.30 & $\begin{array}{c}5.6 \\
0 \\
\end{array}$ & 90 & $\begin{array}{c}0.8 \\
8 \\
\end{array}$ & $\begin{array}{c}3.5 \\
8 \\
\end{array}$ & 0.50 & $\begin{array}{c}1.0 \\
8 \\
\end{array}$ & $\begin{array}{c}15 . \\
1 \\
\end{array}$ & $\begin{array}{c}14 . \\
5 \\
\end{array}$ & $\begin{array}{c}+4 . \\
0 \\
\end{array}$ \\
\hline 4 & $\begin{array}{c}0.6 \\
6 \\
\end{array}$ & $\begin{array}{c}0.3 \\
0 \\
\end{array}$ & $\begin{array}{c}5.4 \\
0 \\
\end{array}$ & $\begin{array}{c}5.5 \\
0 \\
\end{array}$ & 0.57 & $\begin{array}{c}3.8 \\
7 \\
\end{array}$ & 79 & $\begin{array}{c}0.6 \\
2 \\
\end{array}$ & $\begin{array}{c}2.6 \\
9 \\
\end{array}$ & 0.51 & $\begin{array}{c}0.7 \\
3 \\
\end{array}$ & $\begin{array}{c}13 . \\
7 \\
\end{array}$ & $\begin{array}{c}13 . \\
9 \\
\end{array}$ & $\begin{array}{c}- \\
1.4 \\
\end{array}$ \\
\hline 5 & $\begin{array}{c}0.9 \\
5 \\
\end{array}$ & $\begin{array}{c}0.4 \\
6 \\
\end{array}$ & $\begin{array}{c}5.9 \\
0 \\
\end{array}$ & $\begin{array}{c}7.8 \\
0 \\
\end{array}$ & 1.03 & $\begin{array}{c}2.9 \\
1 \\
\end{array}$ & 122 & $\begin{array}{c}0.8 \\
8 \\
\end{array}$ & $\begin{array}{c}2.5 \\
0 \\
\end{array}$ & 0.39 & $\begin{array}{c}1.1 \\
0 \\
\end{array}$ & $\begin{array}{c}16 . \\
1 \\
\end{array}$ & $\begin{array}{c}16 . \\
5 \\
\end{array}$ & $\begin{array}{c}- \\
2.5 \\
\end{array}$ \\
\hline 6 & $\begin{array}{c}0.6 \\
9\end{array}$ & $\begin{array}{c}0.3 \\
7\end{array}$ & $\begin{array}{c}6.6 \\
4 \\
\end{array}$ & $\begin{array}{c}5.6 \\
0 \\
\end{array}$ & 1.21 & $\begin{array}{c}4.2 \\
0 \\
\end{array}$ & 107 & $\begin{array}{c}0.6 \\
9 \\
\end{array}$ & $\begin{array}{c}2.9 \\
2 \\
\end{array}$ & 0.52 & $\begin{array}{c}0.7 \\
8 \\
\end{array}$ & $\begin{array}{c}12 . \\
5\end{array}$ & $\begin{array}{c}13 . \\
6\end{array}$ & $\begin{array}{c}- \\
8.8\end{array}$ \\
\hline 7 & $\begin{array}{c}0.9 \\
6 \\
\end{array}$ & $\begin{array}{c}0.4 \\
6 \\
\end{array}$ & $\begin{array}{c}7.4 \\
4 \\
\end{array}$ & $\begin{array}{c}6.2 \\
0 \\
\end{array}$ & 2.27 & $\begin{array}{c}5.9 \\
0 \\
\end{array}$ & 95 & $\begin{array}{c}0.9 \\
5 \\
\end{array}$ & $\begin{array}{c}4.1 \\
8 \\
\end{array}$ & 0.44 & $\begin{array}{c}1.1 \\
3 \\
\end{array}$ & $\begin{array}{c}15 . \\
2 \\
\end{array}$ & $\begin{array}{c}15 . \\
7 \\
\end{array}$ & $\begin{array}{c}- \\
3.3 \\
\end{array}$ \\
\hline 8 & $\begin{array}{c}1.2 \\
2 \\
\end{array}$ & $\begin{array}{c}0.5 \\
8 \\
\end{array}$ & $\begin{array}{c}7.5 \\
2 \\
\end{array}$ & $\begin{array}{c}7.7 \\
0 \\
\end{array}$ & 2.93 & $\begin{array}{c}5.3 \\
7 \\
\end{array}$ & 107 & $\begin{array}{c}1.1 \\
0 \\
\end{array}$ & $\begin{array}{c}4.0 \\
5 \\
\end{array}$ & 0.40 & $\begin{array}{c}1.4 \\
1 \\
\end{array}$ & $\begin{array}{c}16 . \\
8 \\
\end{array}$ & $\begin{array}{c}16 . \\
4 \\
\end{array}$ & $\begin{array}{c}+2 . \\
4 \\
\end{array}$ \\
\hline 9 & $\begin{array}{c}0.6 \\
4 \\
\end{array}$ & $\begin{array}{c}0.3 \\
8 \\
\end{array}$ & $\begin{array}{c}3.3 \\
0 \\
\end{array}$ & $\begin{array}{c}11 . \\
5\end{array}$ & 1.53 & $\begin{array}{c}3.8 \\
3 \\
\end{array}$ & 29 & $\begin{array}{c}0.6 \\
2 \\
\end{array}$ & $\begin{array}{c}2.9 \\
2\end{array}$ & 0.28 & $\begin{array}{c}0.7 \\
6 \\
\end{array}$ & $\begin{array}{c}21 . \\
6\end{array}$ & $\begin{array}{c}21 . \\
0\end{array}$ & $\begin{array}{c}+2 . \\
8\end{array}$ \\
\hline 10 & $\begin{array}{c}1.3 \\
6 \\
\end{array}$ & $\begin{array}{c}0.6 \\
3 \\
\end{array}$ & $\begin{array}{c}5.9 \\
2 \\
\end{array}$ & $\begin{array}{c}10 . \\
6 \\
\end{array}$ & 2.93 & $\begin{array}{c}4.3 \\
0 \\
\end{array}$ & 88 & $\begin{array}{c}1.2 \\
2 \\
\end{array}$ & $\begin{array}{c}3.3 \\
7 \\
\end{array}$ & 0.37 & $\begin{array}{c}1.5 \\
2 \\
\end{array}$ & $\begin{array}{c}23 . \\
4 \\
\end{array}$ & $\begin{array}{c}22 . \\
5\end{array}$ & $\begin{array}{c}+3 \\
4 \\
\end{array}$ \\
\hline 11 & $\begin{array}{c}1.3 \\
9 \\
\end{array}$ & $\begin{array}{c}0.6 \\
9 \\
\end{array}$ & $\begin{array}{c}7.7 \\
2 \\
\end{array}$ & $\begin{array}{c}8.9 \\
5 \\
\end{array}$ & 3.25 & $\begin{array}{c}2.9 \\
2 \\
\end{array}$ & 155 & $\begin{array}{c}1.3 \\
0 \\
\end{array}$ & $\begin{array}{c}3.1 \\
5 \\
\end{array}$ & 0.37 & $\begin{array}{c}1.6 \\
0 \\
\end{array}$ & $\begin{array}{c}18 . \\
8 \\
\end{array}$ & $\begin{array}{c}18 . \\
7 \\
\end{array}$ & $\begin{array}{c}+0 . \\
5 \\
\end{array}$ \\
\hline 12 & $\begin{array}{c}1.1 \\
7 \\
\end{array}$ & $\begin{array}{c}0.5 \\
4 \\
\end{array}$ & $\begin{array}{c}7.5 \\
8 \\
\end{array}$ & $\begin{array}{c}7.1 \\
0 \\
\end{array}$ & 3.22 & $\begin{array}{c}4.7 \\
7 \\
\end{array}$ & 123 & $\begin{array}{c}1.0 \\
8 \\
\end{array}$ & $\begin{array}{c}3.5 \\
9 \\
\end{array}$ & 0.32 & $\begin{array}{c}1.4 \\
1 \\
\end{array}$ & $\begin{array}{c}16 . \\
5 \\
\end{array}$ & $\begin{array}{c}18 . \\
8 \\
\end{array}$ & $\begin{array}{c}- \\
9.1 \\
\end{array}$ \\
\hline & & & & & chan & el Sue & $\mathrm{li}(\mathrm{Q}=$ & $70 \ldots 1$ & $\mathrm{~m}^{3} / \mathrm{c}$ & & & & & \\
\hline $\begin{array}{l}1 \\
3 \\
\end{array}$ & $\begin{array}{c}0.9 \\
1 \\
\end{array}$ & $\begin{array}{c}0.4 \\
8 \\
\end{array}$ & $\begin{array}{c}5.7 \\
0 \\
\end{array}$ & $\begin{array}{c}8.4 \\
2 \\
\end{array}$ & $\begin{array}{c}4.2 \\
8 \\
\end{array}$ & $\begin{array}{c}3.0 \\
0 \\
\end{array}$ & $\begin{array}{c}11 \\
0 \\
\end{array}$ & 0.91 & $\begin{array}{c}2.2 \\
5 \\
\end{array}$ & $\begin{array}{c}0.3 \\
2 \\
\end{array}$ & 1.09 & $\begin{array}{c}18 . \\
3 \\
\end{array}$ & $\begin{array}{c}20 . \\
5\end{array}$ & $\begin{array}{c}+6 . \\
3 \\
\end{array}$ \\
\hline $\begin{array}{l}1 \\
4 \\
\end{array}$ & $\begin{array}{c}0.9 \\
1\end{array}$ & $\begin{array}{c}0.4 \\
5\end{array}$ & $\begin{array}{c}6.7 \\
5\end{array}$ & $\begin{array}{c}6.7 \\
0 \\
\end{array}$ & $\begin{array}{c}1.8 \\
1 \\
\end{array}$ & $\begin{array}{c}3.7 \\
0 \\
\end{array}$ & $\begin{array}{c}12 \\
5\end{array}$ & 0.87 & $\begin{array}{c}2.7 \\
3\end{array}$ & $\begin{array}{c}0.5 \\
6\end{array}$ & 1.03 & $\begin{array}{c}15 . \\
0\end{array}$ & $\begin{array}{c}14 . \\
1\end{array}$ & $\begin{array}{c}+6 . \\
0\end{array}$ \\
\hline $\begin{array}{l}1 \\
5\end{array}$ & $\begin{array}{c}0.8 \\
8\end{array}$ & $\begin{array}{c}0.4 \\
4\end{array}$ & $\begin{array}{c}7.6 \\
7\end{array}$ & $\begin{array}{c}5.8 \\
2 \\
\end{array}$ & $\begin{array}{c}1.6 \\
9 \\
\end{array}$ & $\begin{array}{c}4.3 \\
0 \\
\end{array}$ & $\begin{array}{c}14 \\
0\end{array}$ & 0.85 & $\begin{array}{c}2.6 \\
7 \\
\end{array}$ & $\begin{array}{c}0.5 \\
9\end{array}$ & 0.98 & $\begin{array}{c}13 . \\
9\end{array}$ & $\begin{array}{c}13 . \\
2\end{array}$ & $\begin{array}{c}+5 . \\
1\end{array}$ \\
\hline $\begin{array}{l}1 \\
6 \\
\end{array}$ & $\begin{array}{c}0.7 \\
7 \\
\end{array}$ & $\begin{array}{c}0.3 \\
4 \\
\end{array}$ & $\begin{array}{c}4.6 \\
4 \\
\end{array}$ & $\begin{array}{c}7.4 \\
0 \\
\end{array}$ & $\begin{array}{c}0.6 \\
4\end{array}$ & $\begin{array}{c}2.4 \\
2 \\
\end{array}$ & $\begin{array}{c}12 \\
2 \\
\end{array}$ & 0.70 & $\begin{array}{c}1.8 \\
0\end{array}$ & $\begin{array}{c}0.4 \\
2 \\
\end{array}$ & 0.88 & $\begin{array}{c}15 . \\
2\end{array}$ & $\begin{array}{c}16 . \\
6\end{array}$ & -9.2 \\
\hline $\begin{array}{l}1 \\
7 \\
\end{array}$ & $\begin{array}{c}0.5 \\
8 \\
\end{array}$ & $\begin{array}{c}0.3 \\
5 \\
\end{array}$ & $\begin{array}{c}4.0 \\
8 \\
\end{array}$ & $\begin{array}{c}8.6 \\
0 \\
\end{array}$ & $\begin{array}{c}0.4 \\
4 \\
\end{array}$ & $\begin{array}{c}1.9 \\
0 \\
\end{array}$ & 88 & 0.59 & $\begin{array}{c}1.4 \\
5 \\
\end{array}$ & $\begin{array}{c}0.3 \\
4 \\
\end{array}$ & 0.70 & $\begin{array}{c}16 . \\
4 \\
\end{array}$ & $\begin{array}{c}17 . \\
8 \\
\end{array}$ & -8.5 \\
\hline $\begin{array}{l}1 \\
8 \\
\end{array}$ & $\begin{array}{c}0.9 \\
3 \\
\end{array}$ & $\begin{array}{c}0.5 \\
5 \\
\end{array}$ & $\begin{array}{c}6.8 \\
1 \\
\end{array}$ & $\begin{array}{c}8.1 \\
0\end{array}$ & $\begin{array}{c}1.1 \\
9\end{array}$ & $\begin{array}{c}3.5 \\
6\end{array}$ & $\begin{array}{c}13 \\
3 \\
\end{array}$ & 0.96 & $\begin{array}{c}2.6 \\
4\end{array}$ & $\begin{array}{c}0.4 \\
2 \\
\end{array}$ & 1.09 & $\begin{array}{c}15 . \\
9\end{array}$ & $\begin{array}{c}16 . \\
4\end{array}$ & -3.1 \\
\hline $\begin{array}{l}1 \\
9 \\
\end{array}$ & $\begin{array}{c}0.8 \\
9 \\
\end{array}$ & $\begin{array}{c}0.4 \\
6 \\
\end{array}$ & $\begin{array}{c}6.3 \\
2 \\
\end{array}$ & $\begin{array}{c}7.3 \\
1 \\
\end{array}$ & $\begin{array}{c}0.9 \\
1 \\
\end{array}$ & $\begin{array}{c}3.2 \\
8 \\
\end{array}$ & $\begin{array}{c}12 \\
4 \\
\end{array}$ & 0.89 & $\begin{array}{c}2.6 \\
2 \\
\end{array}$ & $\begin{array}{c}0.4 \\
5 \\
\end{array}$ & 1.03 & $\begin{array}{c}15 . \\
8\end{array}$ & $\begin{array}{c}16 . \\
0 \\
\end{array}$ & -1.3 \\
\hline $\begin{array}{l}2 \\
0 \\
\end{array}$ & $\begin{array}{c}0.6 \\
2 \\
\end{array}$ & $\begin{array}{c}0.3 \\
4 \\
\end{array}$ & $\begin{array}{c}3.1 \\
0\end{array}$ & $\begin{array}{c}11 . \\
0\end{array}$ & $\begin{array}{c}1.1 \\
9 \\
\end{array}$ & $\begin{array}{c}2.0 \\
8 \\
\end{array}$ & 47 & 0.59 & $\begin{array}{c}1.6 \\
0 \\
\end{array}$ & $\begin{array}{c}0.3 \\
1 \\
\end{array}$ & 0.72 & $\begin{array}{c}21 . \\
8\end{array}$ & $\begin{array}{c}20 . \\
8 \\
\end{array}$ & $\begin{array}{c}+4 . \\
6 \\
\end{array}$ \\
\hline $\begin{array}{l}2 \\
1 \\
\end{array}$ & $\begin{array}{c}0.7 \\
5 \\
\end{array}$ & $\begin{array}{c}0.4 \\
2 \\
\end{array}$ & $\begin{array}{c}4.6 \\
0 \\
\end{array}$ & 9.1 & $\begin{array}{c}1.6 \\
5 \\
\end{array}$ & $\begin{array}{c}2.5 \\
3 \\
\end{array}$ & 86 & 0.75 & $\begin{array}{c}2.0 \\
0 \\
\end{array}$ & $\begin{array}{c}0.3 \\
8 \\
\end{array}$ & 0.87 & $\begin{array}{c}17 . \\
2 \\
\end{array}$ & $\begin{array}{c}17 . \\
2 \\
\end{array}$ & 0.0 \\
\hline $\begin{array}{l}2 \\
2 \\
\end{array}$ & $\begin{array}{c}0.7 \\
6 \\
\end{array}$ & $\begin{array}{c}0.4 \\
0\end{array}$ & $\begin{array}{c}4.2 \\
0 \\
\end{array}$ & 9.5 & $\begin{array}{c}1.6 \\
4 \\
\end{array}$ & $\begin{array}{c}2.2 \\
3 \\
\end{array}$ & 81 & 0.76 & $\begin{array}{c}1.7 \\
0 \\
\end{array}$ & $\begin{array}{c}0.3 \\
7 \\
\end{array}$ & 0.87 & $\begin{array}{c}19 . \\
5 \\
\end{array}$ & $\begin{array}{c}19 . \\
8 \\
\end{array}$ & $\begin{array}{c}+5 . \\
7 \\
\end{array}$ \\
\hline
\end{tabular}


Table 1 continued

\begin{tabular}{|c|c|c|c|c|c|c|c|c|c|c|c|c|c|c|}
\hline \multicolumn{10}{c|}{ channel Kuvanish-djarma $\left(\mathrm{Q}=90 \ldots 136 \mathrm{~m}^{3} / \mathrm{c}\right)$} \\
\hline 2 & 0.9 & 0.5 & 6.1 & 8.5 & 1.8 & 4.0 & 94 & 0.9 & 2.7 & 0.3 & 1.0 & 18. & 17. & +1. \\
3 & 1 & 2 & 0 & & 7 & 3 & & 1 & 0 & 6 & 8 & 1 & 8 & 6 \\
\hline 2 & 0.9 & 0.5 & 6.0 & 9.0 & 1.3 & 4.4 & 88 & 0.9 & 2.8 & 0.3 & 1.1 & 19. & 18. & +5. \\
4 & 7 & 5 & 6 & & 9 & 0 & & 7 & 4 & 0 & 7 & 6 & 6 & 1 \\
\hline 2 & 1.0 & 0.5 & 5.2 & 11. & 3.7 & 3.9 & 72 & 1.0 & 2.7 & 0.3 & 1.2 & 23. & 21. & +9. \\
5 & 6 & 9 & 8 & 2 & 1 & 5 & & 4 & 6 & 6 & 0 & 4 & 1 & 8 \\
\hline 2 & 1.1 & 0.6 & 6.1 & 10. & 4.2 & 4.3 & 89 & 1.0 & 2.8 & 0.3 & 1.3 & 21. & 20. & +4. \\
6 & 7 & 4 & 9 & 4 & 8 & 8 & & 6 & 8 & 1 & 8 & 2 & 3 & 3 \\
\hline 2 & 0.8 & 0.4 & 6.0 & 7.7 & 2.1 & 3.8 & 97 & 0.8 & 2.6 & 0.3 & 1.0 & 16. & 16. & +1. \\
7 & 7 & 7 & 6 & & 1 & 7 & & 3 & 0 & 8 & 3 & 8 & 6 & 2 \\
\hline 2 & 0.8 & 0.4 & 5.0 & 7.5 & 2.1 & 3.6 & 10 & 0.8 & 2.6 & 0.4 & 0.9 & 16. & 16. & 0.0 \\
8 & 4 & 5 & 4 & & 7 & 3 & 3 & 5 & 4 & 0 & 9 & 7 & 7 & \\
\hline 2 & 0.8 & 0.4 & 5.6 & 8.8 & 4.5 & 3.7 & 87 & 0.8 & 2.6 & 0.4 & 1.0 & 18. & 16. & +9. \\
9 & 8 & 8 & 6 & & 8 & 3 & & 7 & 3 & 3 & 2 & 4 & 6 & 8 \\
\hline 3 & 0.8 & 0.4 & 5.7 & 8.7 & 2.3 & 3.4 & 78 & 0.8 & 2.4 & 0.3 & 0.9 & 17. & 19. & +6. \\
0 & 1 & 4 & 0 & & 9 & 0 & & 4 & 4 & 4 & 6 & 6 & 3 & 2 \\
\hline \multicolumn{10}{|c|}{ Average deviation: }
\end{tabular}

Applying the drag formulas using the parameters of the vertical velocity distribution, calculated from the research data, we determined the dependences of the relative roughness $\left(\ln \frac{h}{\Delta}\right.$ ) on the parameter K (Fig. 5), having the following form:

1. $\ln \frac{h}{\Delta}=12,3 K$ - for a flow with turbidity $\rho<3 \mathrm{~kg} / \mathrm{m} 3$,

2. $\ln \frac{h}{\Delta}=15 K$ - for a flow with turbidity $\rho>3 \mathrm{~kg} / \mathrm{m} 3$.

Earlier studies [20] on the influence of turbulent flow turbulence on the size of sand ridges formed by it in the Karakum canal confirmed the relationship between the frequency characteristics of the turbidity flow and the shape of the ridges. So, the heights of the ridges first increase, reach a maximum height when saturated with a turbidity flow of $3.0 \mathrm{~kg} / \mathrm{m} 3$, and then sharply decreases. The relationship between hydraulic resistance and turbidity of the flow was investigated by EK Rabkova [19], where the highest hydraulic resistance is also noted for turbidity of $3.0 \mathrm{~kg} / \mathrm{m} 3$ (Fig. 6).

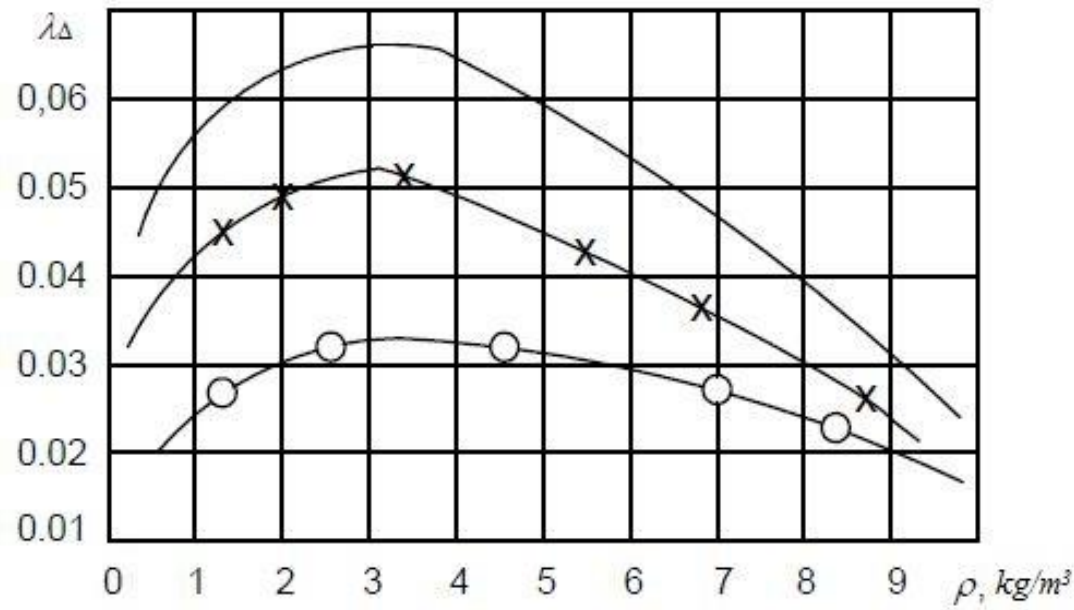

Fig. 6. Change in the coefficient of hydraulic resistance of a turbid flow depending on the concentration of suspended sediment $\rho$ according to the Peoples' Friendship University named after P. Lumumba [19]. 
Apparently, it is possible to speak of a completely revealed pattern that needs theoretical generalization.

Figure 7 shows the distribution of longitudinal velocities and turbidity along the flow depth measured in the Kyzketken and Kuvanyshjarma channels. The analysis of these graphs shows the influence of the turbidity of the flow on the velocity distribution, and the shape of the velocity distribution diagram in a dimensionless form (Fig. 8) also characterizes the mode of sediment movement and the degree of channel stability.

In channels with a rough bottom, with an increase in the height of the roughness ridges, the intensity of movement by turbulent pulsations increases, and the dimensionless velocity gradient $\mathrm{u}_{\mathrm{u}} *$ decreases (see Figure 8 ).

In this case, the coefficient $\mathrm{n}$ increases, which leads to an increase in the parameter $\mathrm{K}$. In a smooth mode, the resistance with a decrease in hydraulic resistance, the dimensionless velocity gradient (see Figure 8), with an increase in turbidity, the value of K.

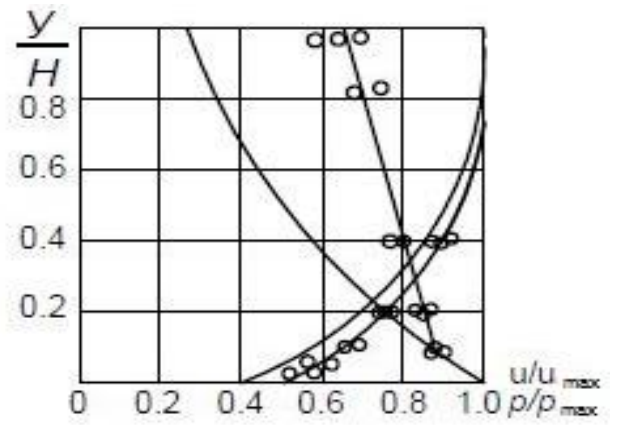

a)

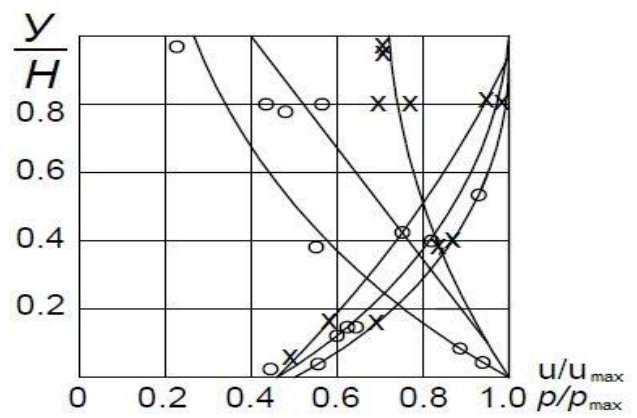

b)

Fig. 7. Diagrams of distribution of longitudinal velocities and turbidity on verticals: in the Kyzketken PK 95 channels (a); Kuvanyshjarma PK 15 (b).

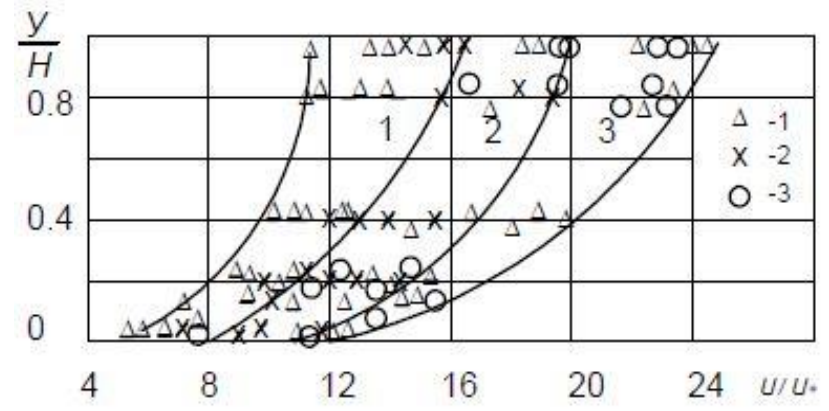

Fig. 8. Distribution of the dimensionless velocity gradient in a turbulent flow: 1 is channel Kyzketken; 2 is channel Suenly; 3 is Kuvanyshjarma channel. I is zone of erosion regime; II is critical mode zone; III is zone of silting regime 


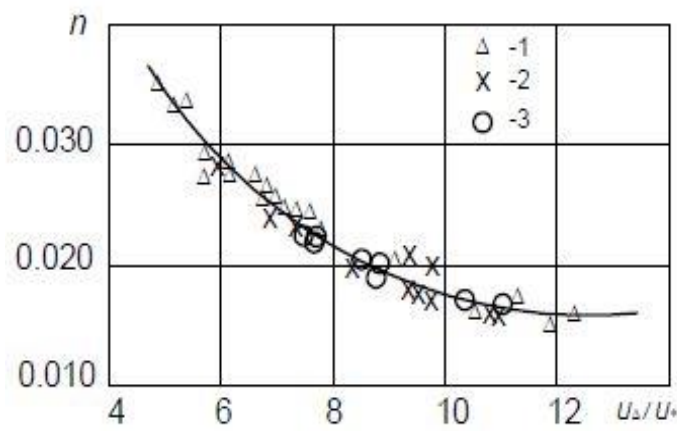

Fig. 9. Graph of dependence of $\mathrm{n}$ on $\mathrm{N}_{-}{ }^{*}=\mathrm{u}_{-} \Delta \mathrm{u}_{-} *$ (designations are the same as in Fig. 8).

The stability parameter of the bottom layer $\mathrm{N}$, for rough channels or the ratio of the bottom velocity at the top of the roughness to the dynamic $\left(\mathrm{N}_{-} *=\mathrm{u}_{-} \Delta \mathrm{u}_{-} *\right)$, increases with its value $\mathrm{n}$. With a decrease in the values of $\mathrm{n}=0.0225$ to 0.018 , according to the measurement data, the ratio of the bottom velocity to the dynamic one increased from 7.5 to 12 (see Figure 9).

\section{Conclusions}

Based on the analysis of some existing theoretical and experimental studies of hydraulic resistances of channel flows by scientists from the CIS and abroad, as well as their own field studies of resistances on large earth channels, the following conclusions were obtained:

1. Possible reasons for the inconsistency of the results of various studies of hydraulic resistances in open channels with increased roughness are identified.

2. The analysis of mass field data on the Darcy (Shezi) coefficient of channels in cohesive and non-cohesive soils in a sandy mobile bed is carried out. These data confirm the earlier assumptions obtained by S.Kh. Abalyants and O.M. Ayvazyan that the quadratic resistance traditionally attributed to these channels does not correspond to reality. The channels of these categories are characterized by a mixed zone of hydraulic resistance. Therefore, the calculation formula for the Shezy coefficient should take into account the features of the real zone of resistance of earthen channels. Judging by the nature of the location of field points in the general connection $\lambda=\lambda(\mathrm{Re}, \mathrm{J}, \mathrm{R})$, it can be assumed that the mixed zone can be divided into two regions (Fig. 1): a) the region for hydraulically smooth channel channels $(\mathrm{J}<0,00005)$; b) area for hydraulically rough channel channels $(\mathrm{J}>0.00007)$.

3. Based on the analysis of the smoothly varying uneven movement of the channel flow and the theory of the boundary layer corresponding to them, as well as using the logarithmic law of the distribution of velocities, the calculated dependences $(6,7)$ were obtained, which make it possible to determine the hydraulic resistance of open suspended streams concerning natural conditions.

4. The dependences in the article based on the measurement data along earthen canals transporting a significant amount of suspended sediment clearly show the regularity of $\mathrm{K}$, $\mathrm{n}$, and $\lambda$ changes depending on the turbidity and mode of their movement.

5. Experts in almost all developed countries of the world are now studying the resistance of natural channels. For the success of this work, contacts between scientists are important. 


\section{References}

1. Gorbachev P.F. Fluid flow rate formulas. - M.:, L .: Stroyizdat. 1936-168 p.

2. Aivazyan OM Comparative assessment of modern formulas for calculating the Shezi coefficient. // Hydraulic engineering and melioration. No. 11. - pp.25-31, (1979)

3. Abalyants S.Kh. Stable and transient regimes in artificial channels. L. Hydrometeoizdat, p. 240, (1981)

4. Shin K., Grigg M.A. Reconsideration of the hydraulics radius as a geometric quantity in open channel hydraulics. - "Proc. XII Congr. SAHR, p.14. (1967)

5. Baymanov K.I. Modes of hydraulic resistance in earthen channels // Uzbek journal "Problem of mechanics" No. 1. -from. pp.34-38, Tashkent. (2014)

6. Lyapin A.N., Polyanskaya N.V. Influence of the free surface on the formation of the ridge bottom of the channel flow. Hydrotechnical construction, No. 5, pp. 27-31. (1989)

7. Snishchenko B.F., Kopaliani Z.D. On the speed of movement of ridges in rivers and laboratory conditions // Proceedings of the State Institute of Geology - L. issue 252. from. Pp.20 - 37, (1978)

8. Mikhailova N.A., On the mechanism of formation and movement of sand waves // Izv. Academy of Sciences of the USSR. Ser. Geophys. No. 1. -from. pp.47-56, (1952)

9. Bogomolov A.I., Borovkov V.S., Mayranovskiy F.G. High speed free surface streams. - M., Stroyizdat.- p.344, (1979)

10. Methodological guidelines for carrying out full-scale hydraulic studies on existing earthen canals. - M. Soyuzgiprovodhoz. - p.60, (1984)

11. Bekimbetov N.B. Baymanov K.I. On the influence of suspended sediment on the hydraulic resistance of the channel // Hydrotechnical construction. No. 1. -from. pp.29-31, (1982)

12. Baymanov K.I. The structure of a turbulent flow with a ridge bottom // Uzbek journal "Problem of mechanics" No. 1. - pp. 86-90, Tashkent. (2016)

13. Baymanov K.I., Shaniyazov G.T. Hydraulic resistance of easily deformable channels // Uzbek journal "Problem of mechanics" No. 4. -from. pp. 23-26, Tashkent. (2006)

14. Baymanov K.I. Kinematic structure of the flow in earthen channels. //Hydraulic engineering. M., no. 3 - pp.37 - 40, (2005)

15. Zegzhda A.P. Hydraulic friction losses in channels and pipelines. M. - L. Gosstroyizdat. — p.278, (1981)

16. Grishanin K.V. Hydraulic resistance of natural channels. St. Petersburg. Hydrometeoizdat. - p.180, (1992)

17. V.S. Altunin Reclamation canals in the earthen bed. - M.,-p.256, Kolos, (1979)

18. Znamenskaya N.S. Dependence of the types of channel process on the hydraulic characteristics of the flow and sediment. // Metrology and Hydrology. M. No. 11. pp.65-74, (1976)

19. Rybakova E.K. Hydraulic resistances in the eroded bed. // In the book: River hydraulics and hydraulic engineering. M., -pp.105 - 111. (1973)

20. Balakaev B.K., Lyapin A.N. On the ridge hydraulic resistance of turbid channel flows. //Hydraulic engineering. M., no. 7 - pp. 20 - 22, (1990)

21. Monin A.S., Yaglom A.M. Static hydrodynamics. - M. Science.-p.640, (1965)

22. Vanoni V.A. Factors, determining bed forms of alluvial streams. - J. Hydr. Div. Proc. ASCE. vol. 100, no. 3. - pp.363 - 377, (1974)

23. Einstein H.A., Barbarossa N.L. River channel roughness. Trans. ASCE., 117, pp.1121 -1132 , (1952)

24. Kennedy J.F. The formation of sediment ripples, dunes and anti-dunes. - Annual Rev. Fluid. Mech, 1. - Palo Alto Calif, Annual Revs, pp. 147-168. (1969) 